\title{
Study on prevalence of Diabetes Mellitus in patients with Pulmonary Tuberculosis
}

\section{Lokesh Gutta *1, Rajender 2, Meghana S ${ }^{3}$, Jhansi Rani ${ }^{4}$.}

${ }^{1}$ Third Year PG, Department of Pulmonology, Chalmeda Anand Rao Institute of M edical Sciences, Karimnagar, Telangana, India.

${ }^{2}$ Prof \& HOD, Department of Pulmonology, Chalmeda Anand Rao Institute of M edical Sciences, Karimnagar, Telangana, India.

${ }^{3}$ Second Year PG, Department of Pulmonology, Chalmeda Anand Rao Institute of M edical Sciences, Karimnagar, Telangana, India.

${ }^{4}$ Assistant Professor, Department of Biochemistry, Chalmeda Anand Rao Institute of Medical Sciences, Karimnagar, Telangana, India.

\section{ABSTRACT}

Background: A rising prevalence of tuberculosis in diabetics has been seen with age. Active tuberculosis intensifies diabetes mellitus and vice versa; thus, the two diseases constitute a dreaded companion. The dual burden of disease may make the management of both conditions more difficult. Mortality rates in these patients are reported to be several times higher than in non-diabetic pulmonary tuberculosis patients.

Aim: To study the prevalence of diabetes mellitus in patients with Tuberculosis.

Materials and Methods: 400 patients diagnosed as pulmonary tuberculosis at Chalmeda Anand Rao Institute DOTS centre were included in this study.This study was conducted from M arch 2014 to December 2015. Fasting plasma glucose levels of patients diagnosed with tuberculosis were analyzed and were being managed as per DOTS guidelines.

Results: 400 cases taken up for this study, 256 were males (64\%) and 144 were females (36\%), the total number of patients found diabetic were $46(11.5 \%)$. Amongst males 28 (10.9\%) were found diabetic, of whom known diabetics were 10 (35.7\%) (eight on OHA and two on Insulin) and females found diabetic were 18(12.5\%), of whom 8 (44\%) were known diabetics (six OHA and two Insulin).The total number of diabetics when analyzed was 44 Type II and two Type I.

Conclusion: In view of the high prevalence of diabetes mellitus, it is recommended that Standard Screening programme for diabetes should be incorporated under DOTS so that early diagnosis and treatment can be done to avoid morbidity and failure of Category-I patients under DOTS.

KEY WORDS: Diabetes mellitus, Pulmonary tuberculosis, HbA1C, Chest X-ray.

Address for correspondence: Dr. Lokesh Gutta, Third yr PG, Department of Pulmonology, CAIM S, Karimnagar-505001. Telangana, India. E-M ail: meghareddy15@gmail.com

\begin{tabular}{|c|c|c|}
\hline \multicolumn{3}{|c|}{ Online Access and Article Informtaion } \\
\hline \multirow{2}{*}{$\begin{array}{c}\text { Quick Response code } \\
\text { Dol: } 10.16965 / \text { ijims.2016.125 }\end{array}$} & \multicolumn{2}{|c|}{$\begin{array}{l}\text { International Journal of Integrative Medical Sciences } \\
\text { www.imedsciences.com }\end{array}$} \\
\hline & $\begin{array}{l}\text { Received: 06-06-2016 } \\
\text { Reviewed: 06-06-2016 }\end{array}$ & $\begin{array}{l}\text { Accepted: 14-06-2016 } \\
\text { Published: 30-06-2016 }\end{array}$ \\
\hline Source of Funding: Self & & Jone \\
\hline
\end{tabular}

\section{BACKGROUND}

Tuberculosis can be traced back to the early history of mankind. Despite all efforts to eliminate tuberculosis, it continues to be one of the most prevalent infection in the world. The seriousness of the association of pulmonary 
tuberculosis and diabetes mellitus was first noted by the great Arab Physician Avicenna nearly 1000 years ago. The link between diabetes mellitus and pulmonary tuberculosis has been talked of at various fora but has never occupied the centre stage of discussions. Presently, an epidemic of diabetes is on both in developed and developing nations. With the recognization of this explosive, increase in the number of people diagnosed with diabetes mellitus all over the world, a whole new field of issues related to interaction between diabetes and pulmonary tuberculosis has been laid open. Diabetes mellitus (DM) is a known risk factor for pulmonary tuberculosis (PTB) [1].

Reported incidence of tuberculosis in India, as per WHO, in 2014 was 167/100,000 and there are about 17 deaths/ lac population in India. The prevalence of diabetes and TB has ranged from $1.6 \%$ to $8.4 \%$ in various studies $[2,3,4,14]$.

The global figure of people with diabetes is projected to rise from the current estimate of 220 million in 2010 to 300 million in 2025. M ost cases will be of type II diabetes, which is characterized by insulin resistance and/or abnormal insulin secretion. In India, the number of cases of diabetes is 23 million in 2003 to 57 million in 2025 [3].

A rising prevalence of tuberculosis in diabetics has been seen with age. Active tuberculosis intensifies diabetes mellitus and vice versa; thus, the two diseases constitute a dreaded companion. The dual burden of disease may make the management of both conditions more difficult. Mortality rates in these patients are reported to be several times higher than in nondiabetic pulmonary tuberculosis patients. Tuberculosis is more frequent in diabetics than in non-diabetics [13]. Diabetes increases the risk of developing tuberculosis, especially in developing countries with a high incidence of tuberculosis [11].

The large dual burden of disease may make management of both conditions more difficult [16]. The only way to counter dreadful combination is to insist on a routine blood sugar screening test in tuberculosis patients and carry out sputum and chest $X$-ray examination in diabetics once a year or on any occasion when cough persists for a month or the insulin requirement suddenly goes up.

Aims and Objectives: To study the prevalence of diabetes mellitus in patients with tuberculosis.

\section{MATERIALS AND METHODS}

Study Setting: The study was a prospective study conducted at Chalmeda Anand Rao Institute of M edical Sciences, Karimnagar, India. It was undertaken to evaluate the presence of undiagnosed diabetes under DOTS strategy. Fasting plasma glucose levels of patients diagnosed with tuberculosis were analyzed and were being managed as per DOTS guidelines.

Study Unit: Patients diagnosed as pulmonary tuberculosis as per RTNCP guidelines at Chalmeda Anand Rao Institute DOTS centre, Karimnagar, from the period of $2014 \mathrm{M}$ arch to 2015 December were included in this study.

Sample Size: 400 patients diagnosed as pulmonary tuberculosis at Chalmeda Anand Rao InstituteDOTS centre were included in this study. The sample size was calculated as per automated method by SPSS Inc. \&Chicago 17.0 V. An institutional ethical clearance was obtained. A simple fasting plasma glucose level blood sample was taken through fully automated analyzer (DS-302).

Procedure: The diagnosis of diabetes mellitus was established from the Clinical symptoms and the estimation of blood sugar levels. ${ }^{10} \mathrm{All}$ diagnosed pulmonary tuberculosis patients were tested for fasting blood sugar, the right/left index finger area was cleaned with antiseptic and pricked with a sharp needle or a lancet and a drop of blood was taken for the serum blood glucose. Patients with a fasting plasma glucose of $>7 \mathrm{mmol} / \mathrm{L}(126 \mathrm{mg} / \mathrm{dL})$ were categorized as diabetics based on samples taken through fully automated analyzer (DS-302). Glucose was estimated by "GOD - PAP" enzymatic photometric test methodology. ${ }^{17,18}$ All those patients who were diagnosed with diabetes were then subjected to $\mathrm{HbA1C}$ (glycosylated hemoglobin testing) by enzyme-based enzymatic assay to see their control. Those who were $\mathrm{HbA1C}>6 \%$ were confirmed to be diabetics (normal range 4.5-6.0\%). The same test was 
conducted in the Department of Biochemistry, Chalmeda Anand Rao Medical Institute, Karimnagar, India.

Inclusion Criteria: All patients diagnosed as pulmonary tuberculosis at Chalmeda Anand Rao Institute, DOTS centre were included in the study.

Exclusion Criteria: All patients aged $<15$ years, hypertensive patients, patients on any corticosteroid therapy as in COPD, asthma or patients in morbid state or with major systemic illnesses were excluded.

\section{RESULTS}

Fig. 1: Sex wise total patients under study and their known and unknown diabetic status.

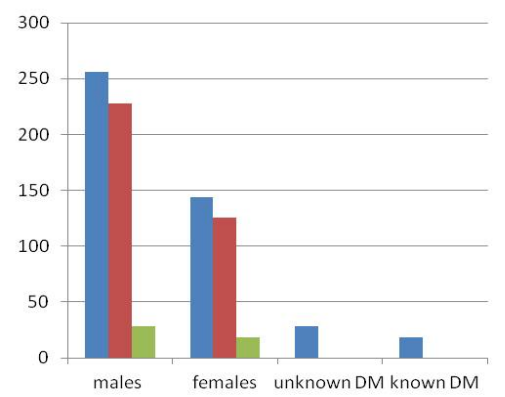

Total patients

non DM - DM

Table 1: Sex wise distribution of patients into diabetics and non diabetics.

\begin{tabular}{|c|c|c|c|}
\hline & Males & Females & Total patients \\
\hline Total & 256 & 144 & 400 \\
\hline Non diabetics & 228 & 126 & 354 \\
\hline Diabetics & 28 & 18 & 46 \\
\hline Freshlydiagnosed & 18 & 10 & 28 \\
\hline Known diabetic & 10 & 8 & 18 \\
\hline
\end{tabular}

The multiple bar diagram (Figure 1) suggests that out of the 400 cases taken up for this study, 256 were males (64\%) and 144 were females (36\%), the total number of patients found diabetic were 46 (11.5\%). Amongst males 28 $(10.9 \%)$ were found diabetic, of whom known diabetics were 10 (35.7\%) (eight on OHA and two on Insulin) and females found diabetic were $18(12.5 \%)$, of whom 8 (44\%) were known diabetics (six OHA and two Insulin).The total number of diabetics when analyzed was 44 Type

Int J Intg M ed Sci 2016;3(6):303-08. ISSN 2394 - 4137
II and two Type I.

Of these 46 patients, 18 were already suffering from diabetes and were on irregular treatment (14 on oral hypoglycemic drugs and 4 on insulin). 28 patients were diagnosed during the course of the study (Figure 1 and Table 1).

Of the 400 patients, $280(70 \%)$ patients were under Category I, while 120(30\%) patients were under Category II. When category-wise analysis of diabetic subjects was done, it was found that patients under Category-I were 15 (32.6\%), patients under Cat-II were 31(67.39\%) (Figure 2 and Table 2).

Table 2: Category wise diabetic patients.

\begin{tabular}{|c|c|}
\hline $\begin{array}{c}\text { Category } \mathbf{1} \\
(\mathbf{n}=\mathbf{2 8 0}) \mathbf{7 0 \%}\end{array}$ & $15(32.6 \%)$ \\
\hline $\begin{array}{c}\text { Category } \mathbf{2} \\
(\mathbf{n}=\mathbf{1 2 0}) \mathbf{3 0 \%}\end{array}$ & $31(67 \%)$ \\
\hline $\begin{array}{c}\text { Total } \\
(\mathbf{n}=\mathbf{4 0 0}) \mathbf{1 0 0} \%\end{array}$ & $46(11.5)$ \\
\hline
\end{tabular}

Fig. 2: Category wise analysis of diabetics under DOTS.

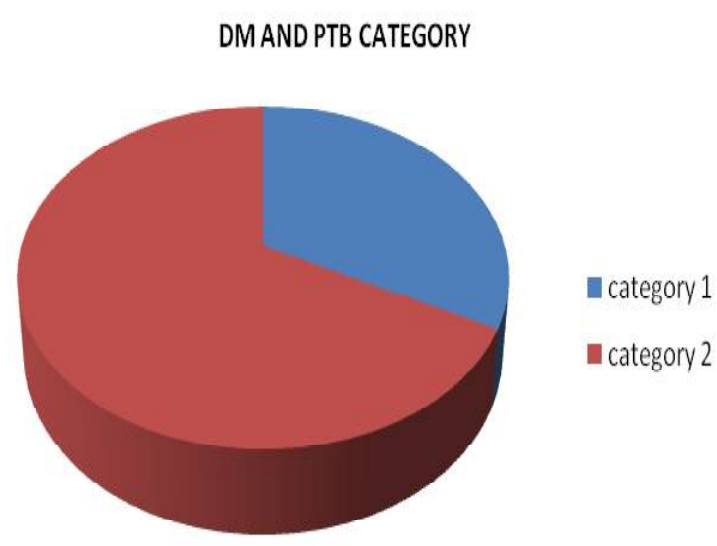

Currently, an epidemic of diabetes is seen both in developed and developing nations. In India,the number of diabetics is estimated to increase from 23 million in 2003 to 57 million in 2025. Reported incidence of tuberculosis in India, as per WHO in 2014, is $167 / 100,000$ and there are about 17-deaths/lac population in India. In 2001, Ramachandran et al [19] (in India) and Alfredo Pone de leon et al [20] (in M exico) found Pulmonary Tuberculosis (PTB) to be five to six times more common among diabetics than non-diabetics and causes greater mortality. In our cross-sectional study of DOTS subjects, out of 400 patients, the prevalence of diabetes was $11.5 \%(n=46)$.Several previous studies on the 
prevalence of both diabetes and tuberculosis together were conducted before the initiation of RNTCP. The prevalence of diabetes and TB has ranged from $1.6 \%$ to $8.4 \%$ in various studies [4-9]. The higher prevalence in the present study can be explained by the large number of patients in CAT II, i.e. 31 patients $(25.8 \%)$ of the total, who had diabetes mellitus and could be the reason for failure under Cat I. Alisjahbana $B$, et al [21]. also suggested that there is a delay in sputum conversion of diabetics versus nondiabetics. This has also been supported by Banu Rekha VV, et al [22] and Guler M et al [23]. They have all suggested a 7-10 day delay in sputum conversion. When the study was subjected to $\mathrm{HbAlC}$, it showed a poor glycemic control, more so in Category II patients. It is reported that strict glycemic equilibrium is essential for the success of antitubercular therapy among diabetes-tuberculosis patients [24]. Studies on the prevalence of diabetes with tuberculosis in DOTS are lacking in literature. In this present study, we observed that the prevalence of diabetes in tuberculosis was $11.5 \%$ in DOTS patients. The figure seems to be quite high compared with earlier individualized studies, which vary from $1.6 \%$ to $8.4 \%$. Data regarding patients in India suffering from both the diseases concomitantly under DOTS is lacking. Recent systematic reviews [25] suggest that Type 2 diabetes mellitus increases individual risk of M ycobacterium tuberculosis (TB) disease.

Country-level analysis suggests that TB prevalence is mediated both by social determinants and public health strategies $[26,27]$. Yet, strikingly little work has been done to assess the relationship between TB and diabetes at the individual level in countries where TB prevalence is the highest and diabetes prevalence is rising rapidly. An increasing prevalence of diabetes may counteract the positive effects of improved curative services for TB. Globally, the incidence of tuberculosis is declining very slowly, and the non communicable disease (NCD) burden for many countries is steadily increasing [28].

Speeding up the decline in incidence will require both scaling up of diagnostic and curative services and additional preventative action, including addressing diabetes and other risk factors that increase the individual's susceptibility to TB [29]. Out of the 400 , the total number of patients in CAT- I was 280, 120 in Category II. When category-wise analysis of these 46 diabetic subjects in this study was done, it was found that patients under CAT-I were 15 (32.6\%), under Cat-II 31 (67.3\%) (Fig. 2).

There is paucity of data regarding the outcome of treatment among TB patients with associated diabetes. Pabloz Mendes et al [30] have also suggested that the adverse effects of diabetes on the treatment outcome of TB patients may result in an increased rate of failures, deaths, defaults and relapses. M ortality rates in these patients are reported to be several times higher than in non-diabetic pulmonary TB patients and the pattern of tuberculosis in diabetics differed from non-diabetics [31]. Diabetic patients were 8.6 times as likely to have infection from diabetes and were on irregular treatment (14 on oral hypoglycemic drugs and 4 on insulin) all in Cat-I. The rest 28 patients (60\%) were diagnosed during the course of our study (Fig. 1).

Type 2 DM may be the sleeping giant of TB. The sheer number of patients who have type $2 \mathrm{DM}$ and exposure to TB may have significant global impact. One of the reasons for high CAT-II patients in the present study could be that patients were having undetected diabetes and were not screened, leading to delayed sputum conversion and failure. Diabetes also impacts TB by tripling the rate of development of active TB from latent TB infection, increasing the mortality and severity of the disease and slowing the response to effective TB treatment [32]. Oursler KK, et al in their study based on clinical and molecular epidemiologic factors in patients survival rate suggested that only diabetes and renal disease remained independent predictors of death [33]. Due to its increasing co-existence, along with lack of detection, initiating antitubercular therapy (ATT) in diabetics is a challenge. Those diabetics, who finally do not respond well to $A T T$, may have higher chances of M DR TB than non-diabetics.

Bashar $M$, et al suggested that $36 \%$ of the patients with diabetes and TB had MDR-TB, compared to only $10 \%$ in the control group [34]. Fisher- Hoch SP et al in their study found that 
Type 2 DM was significantly associated with M DR-TB in a univariate analysis [35]. SuárezGarcía et al have also suggested that diabetes is also one of the most important risk factors for multi-drug resistant tuberculosis in a tuberculosis unit in Madrid, Spain [36].

It has been observed that the prevalence of diabetes will continue to rise rapidly in developing countries, driven by changes in diet, lifestyle and globalization [37]. India, China, Indonesia, Pakistan and Brazil alone are projected to carry nearly half the world's diabetes burden [37]. In many countries, TB epidemics continue, fuelled by drug resistance [38], HIV/AIDS [39,40] and social inequalities [41]. Diabetes comorbidity substantially exceeded that of HIV/AIDS [12]. The impact with a multidrug resistant strain of tuberculosis. It was also highly noticeable that out of those 46 patients, only 18 knew that they were suffering of diabetes/TB interaction may play a substantial role in fuelling the ongoing TB epidemic in India [42].

\section{CONCLUSION}

In view of the high prevalence of diabetes mellitus, it is recommended that Standard Screening programme for diabetes should be incorporated under DOTS so that early diagnosis and treatment can be done to avoid morbidity and failure of Category-I patients under DOTS.

\section{REFERENCES}

[1]. Wang CS, Yang CJ, Chen HC, et al. Impact of type 2 diabetes on manifestations and treatment outcome of pulmonary tuberculosis. Epidemiol Infect 2009;137:203-10.

[2]. King H, Aubert RE, Herman WH: Global burden of Diabetes 1995-2025: Prevalence, Numerical Estimates and projections. Diabetes Care 1998;21:1414.

[3]. World Health Organisation. WHO Report 2008: Global Tuberculosis control, surveillance, planning, financing. WHO/HTM/TB/2008;393:109112.

[4]. Boucot KR et al. Tuberculosis among diabetics: the Philadelphia survey. Am Rev of Tub 1952; 65(1:2):150.

[5]. Oscarsson PNS, H. Incidence and coincidence of diabetes mellitus and pulmonary tuberculosis in a Swedish county. Acta Med Scand Suppl 1958;335:22-48.
[6]. Davidovich D, Aiello CR, Hassan IA. Antitubercular preventive examination in diabetics. Sem Med 1963;122:781-4.

[7]. Nanda, C.N., Tripathy, S.N. J of Assoc of Phy of India 1968;16:714.

[8]. Lahiri, D.C. and Sen, P.K. Indian J Tuberc 1974;21:989.

[9]. Bahulkar, H.V., Lokhandwala,V.A. Tuberculosis - the social evil. Indian Med J 1951 Feb; 45(2): 445.quoted by Deshmukh, 1975.

[10]. Ezung T, Devi NT, Singh NT, Singh TB. Pulmonary tuberculosis and diabetes mellitus-a study. Journl of Ind Med Assoc 2002;100:376-80.

[11]. Kawamori R. Diabetes and tuberculosis-bad companions. Kekkaku 2004;79(1):25-32.

[12]. B. I. Restrepo, S. P. Fisher-Hoch, J.G. Crespo, et.al. Type 2 diabetes and tuberculosis in a dynamic binational border population. Epidemiol Infect 2007;135:483-91.

[13]. M boussa J, M onabeka H, Kombo M, et.al. Course of pulmonary tuberculosis in diabetics. Rev Pneumol Clin 2003;59:39-44.

[14]. Amrit Guptan, Ashok shah.Tuberculosis and Diabetes:An appraisal. Ind J Tub 2000;47:3.

[15]. Hendy M, Stableforth D. The effect of established diabetes mellitus on the presentation of infiltrative pulmonary tuberculosis in the immigrant Asian community of an inner city area of the United Kingdom. Br J Dis Chest 1983;77:87-90.

[16]. Harries AD - Trans R. Links between diabetes mellitus and tuberculosis: should we integrate screening and care? Soc Trop M ed Hyg 01-JAN-2009;103(1):12.

[17]. Jhansi Rani C. Role of Albumin In Estimation of $\mathrm{Hbalc}$ In South Indian Subjects. Int J of Sc Research.2016;5(4):650-651.

[18]. Coleman PG, Thomas DW, Zimmet PZ et al. Community Organizations for diabetes Action, New classification and criteria for the diagnosis of diabetes mellitus; Interpretation of Capillary Blood Glucose Values Revision Date: September 2006

[19]. Ramachandran A, Snehalatha C, Kapur A, et al. High prevalence of diabetes and impaired glucose tolerance in India: National Urban Diabetes Survey. Diabetologia2001;44(9):1094-101.

[20]. Alfredo Pone de leon MD, Ma, De Lourdes Garcia Garcia,Cecila Garcia Sancho. TB and diabetes in Southern M exico. Diabetes Care 2004;27:1584-90.

[21]. Alisjahbana B, Sahiratmadja E, Nelwan EJ, et al. The effect of type 2 diabetes mellitus on the presentation and treatment response of pulmonary tuberculosis. Clin Inf Dis 2007;45:428-35.

[22]. Banu Rekha VV, Balasubramanian R, Swaminathan $S$, et al. Sputum conversion at the end of intensive phase of category-1 regimen in the treatment of pulmonary tuberculosis patients with diabetes mellitus or HIV infection: an analysis of risk factors. Ind J Med Res 2007;126:452-8.

[23]. Guler M, Unsal E, Dursun B, et.al. Factors influencing sputum smear and culture conversion time among 
patients with new cases of pulmonary tuberculosis. Int J Clin Pract 2007;61:231-5.

[24]. Report of the Expert Committee on the Diagnosis and Classification of Diabetes Mellitus. Diabetes Care 2003;26: 12-4.

[25]. Stevenson CR, Critchley JA, Forouhi NG, et al. Diabetes and the risk of tuberculosis: a neglected threat to public health? Chronic IIIn 2007;3:22845.

[26]. Dye C, Lonnroth K, Jaramillo E, Williams BG, Raviglione M. Trends in tuberculosis incidence and their determinants in 134 countries. Bull World Health Organ 2009;87: 683-91.

[27]. Lonnroth K, Jaramillo E, Williams BG, Dye C, Raviglione M. Drivers of tuberculosis epidemics: the role of risk factors and social determinants. Soc Sci Med 2009;68: 2240-6.

[28]. Creswell J, Raviglione M, Ottmani S, Migliori GB, Uplekar M, et al. Tuberculosis and noncommunicable diseases: neglected links and missed opportunities. Eur Res J 2011 M ay;37(5):1269-82.

[29]. Anil K, Anthony D, Harries, Knut Lönnroth, IbC Bygbjerg and Pierre Lefebvre. Diabetes and Tuberculosis - Old associates posing a renewed Public Health Challenge. European Endocrinology 2009;5(1):10-2.

[30]. Pablos-M endez A, Blustein], Knirsch CA. The role of diabetes mellitus in the higher prevalence of tuberculosis among Hispanics. Am J Public Health 1997;87:574-9.

[31]. M eghan A Baker, Anthony D Harries, Christie YJeon, Jessica E Hart, Knut Lönnroth et al. The impact of diabetes on tuberculosis treatment outcomes: A systematic review. BM C M edicine 2011;9:81.

[32]. Perez-Guzman C, et al. Progressive age-related changes in pulmonary tuberculosis images and the effect of diabetes. American Journal of Respiratory and Critical Care Medicine 2000;162:1738-40.
[33]. Oursler KK, et al. Survival of patients with pulmonary tuberculosis: clinical and molecular epidemiologic factors. Clinical Infectious Diseases 2002;34:752-9.

[34]. Bashar M, et al. Increased incidence of multidrug resistant tuberculosis in diabetic patients on the Bellevue Chest Service, 1987 to 1997. Chest 2001;120:1514-9.

[35]. Fisher-Hoch SP, Whitney E, M ccormick JB, Crespo JG, SmithB, Perez AP, et al. Type 2 diabetes and multidrug-resistant tuberculosis. Scand J Infect di 2008;40:888-9336.

[36].Suarez-García I, Rodríguez-Blanco A, VidalPérezGarcía-Viejo M L, Jaras-Hernandez MJ, López OJ, et al.Risk factors for multidrug-resistant tuberculosis in a tuberculosis unit in M adrid, Spain. Eur J Clin Microbiol Inf Dis 2009;28:325-30.

[37]. Wild S, Roglic G, Green A, Sicree R, King H. Global prevalence of diabetes: estimates for the year 2000 and projections for 2030. Diabetes Care 2004;27:1047-53.

[38]. Raviglione M . XDR-TB: entering the post-antibiotic era? Int J Tub Lung Dis 2006; 10:1185-7.

[39]. Corbett EL, Watt CJ, Walker N, et al. The growing burden of tuberculosis: global trends and interactions with the HIV epidemic. Arch Intern Med 2003;163:1009-21.

[40]. Wells CD, Cegielski JP, Nelson LJ, et al. HIV infection and multidrug-resistant tuberculosis: the perfect storm. J Infect Dis 2007;196 Suppl. 1:S86-107.

[41]. Lonnroth K, Jaramillo E, Williams BG, Dye C, Raviglione M. Drivers of tuberculosis epidemics: the role of risk factors and social determinants. Soc Sci Med 2009;68: 2240-6.

[42]. Stevenson CR, Forouhi NG, Roglic G, et al. Diabetes and tuberculosis: the impact of the diabetes epidemic on tuberculosis incidence. BM C Public Health 2007;7:234.

\section{How to cite this article: \\ Lokesh Gutta, Rajender, M eghana S, Jhansi Rani. Study on prevalence of Diabetes Mellitus in patients with Pulmonary Tuberculosis. Int J Intg M ed Sci 2016;3(6):303-308. Dol: 10.16965/ijims.2016.125}

